\title{
Creativity is a Label for the Aggregated, Time - Dependent, Subjective Judgments by Creators and by Adopters
}

\author{
Seana Moran \\ Clark University, USA \\ E-mail address: SMoran@clarku.edu
}

\section{ARTICLE INFO}

\section{Keywords:}

Creativity judgment

Vygotsky

\section{Article history:}

Received 31 October 2014

Received in revised form 19 December 2014

Accepted 20 December 2014

ISSN: 2354-0036

DOI: 10.1515/ctra-2015-0009
A B S T R A C T

The first premise is that creativity requires a focal perceiver perspective to be determined or assigned. As criteria for perception or judgment, what we currently consider "dimensions" of creativity instead may be "precursors." Ultimately, creativity shifts meaning for the whole culture. The second premise is that creativity requires a temporal perspective: its assessment is time-dependent on the first instance the perceiver notices. If the perceiver accepts the creative "it," then it is shared for others to judge it, creating a diffusion and adaptation process. The strongest form of creativity, then, is when it stands the test of time, goes beyond its own zeitgeist, and is institutionalized for future generations.

I applaud the thought and energy that Vlad Glăveanu has injected into the scholarly literature on creativity in the last few years. It is clear that he cares deeply about the phenomenon and experience of creating. I appreciate - and share - his foundations in Vygotskian and Bourdieuan person-culture interactional systems approaches (e.g., Moran, 2009; 2010; Moran \& John-Steiner, 2003). And I hope he succeeds in his campaign to revolutionize our ways of understanding creativity as a concept.

Glăveanu's "The Psychology of Creativity: A Critical Reading" has a long pedigree. Every few years, an influential scholar proclaims that: creativity is not well defined as a concept; the object of creativity - act, person, group, community, outcome, domain, etc. - lacks agreement; what counts as creativity - personal variations/expressions versus moderate influence on others versus historic transformations - continues to expand; creativity measures incompletely or ineffectively capture what creativity is; what it takes for creativity to occur involves so many factors as to be incomprehensible, and so on (e.g., Barron \& Harrington, 1981; Becker, 1995; Feldhusen \& Goh, 1995; Gardner, 1988; Guilford, 1970; Hennessey \& Amabile, 2010; Mumford, 2003; Plucker \& Run- 
co, 1998; Runco, 2004; Simonton, 2000; Sternberg \& Lubart, 1996).

It is as if, as a scholarly community, we aim to "practice what we preach," in terms of judgment-free divergence or self-expression, to such an extent that we repeatedly fail to converge on common definitions or methods as foundational for further intellectual progress. Rather, we continue to expand the boundaries of the concept of creativity to the point that, perhaps, the word is becoming meaningless. Many correlates, components, aspects, and dimensions of creativity often end up being thought of as creativity itself.

Glăveanu presents more provocative claims and suggestions than I can possibly address in one commentary. Therefore, I take two of his suggestions as premises and elaborate on them to see where they lead. The first premise is that what creativity is depends on who is perceiving or describing it. The second premise is that creativity is timedependent. I base these two premises on Vygotsky's theories of meaning and meaningmaking (Moran \& John-Steiner, 2003) by focusing on shift in meaning, which I simply call "it," because it can come in many vehicles. These vehicles are the subject of the "where is creativity?" conundrum (in the person, product, act, etc.; see Csikszentmihalyi, 1996), which I aim to sidestep by calling the shift in meaning "it."

\section{First, who says "it" is creativity?}

In part, whether "it" is creativity depends on the purposes, motives, and perspectives of the person using the term: creativity requires a focal perspective to be determined or assigned. Educators need "mini" and "personal" and "everyday" and "little-c" creativity to be able to have something to study using student or layperson samples. Historians need "historical" or "transformational" or "big-c" creativity to have something to study because the more everyday forms often are not recorded for posterity. Organizational leaders and entrepreneurs need "adaptive" or "middle-c" creativity because their products or services cannot be too familiar nor too unusual or eccentric, or they fail to catch on and be successful in the market in the near term.

Psychology scholars need creativity to be related to mind or behaviour so they can legitimately study it within their field - information processing, aesthetic reaction, judgment, motivation, volition. Sociologists need creativity to be shared and transmitted, perhaps including power gradients, so they can legitimately study the communities and networks that form. Engineers and designers need it to be useful and adaptive; artists need it to be expressive and provocative; city leaders and planners need it to be visible through symbols for creators (as, counterintuitively, "like-minded" creative people can find each other and converge into a class).

As an intellectual exercise, what if we take the word "creativity" away (temporarily), 
and give different terms to the various manifestations of what is now called creativity? There is not room in this short commentary to do more than start the thinking and invite the reader to continue with the exploration. We could start with any of the dimensions of creativity and consider whether "it" is creative: novelty and usefulness are the two most common dimensions, but other dimensions that have been considered include aesthetics (beautiful/elegant to repulsive), quality (excellence to mediocrity), effect (redundant/repetitive to transformational), ethic (good/evil), and manifestation (potential to action to artifact).

However, these other dimensions tend to be dismissed based on their inability to distinguish creativity from other concepts, as scholars could come up with examples of creativity at both ends of each spectrum. Creativity can be both beautiful and ugly, good and evil, redundant and transformational, an action that creates an artifact that generates potential, and of varying degrees of quality. But these dimensions are still used depending on the relevance to the specific purpose of the person claiming creativity.

So we return to the novel and the useful as dimensions used as criteria for judgment. We could argue that usefulness is the more foundational dimension because if "it" is not useful to some entity, it will not be retained or perpetuated - physically, intellectually, socially, culturally, or historically. We have limited resources, and we try not to spend those resources on the useless. Some confusion arises because some examples of creativity involve making an "it" that was formerly considered useless into something useful, even if "it" is not actually novel. Examples include jewellery made from old beer can tabs, purses made from discarded hardbound book covers, effluent used to water lawns, all forms of collages, or failed glue that became Post-lt Notes.

Most often, creativity is tied to novelty, unusualness, difference - something that surprises the person who comes across "it": creativity is in the eye of the beholder, the beholder's background, experience, role/position, and purpose. If "it” is accepted as useful by the beholder and is also the most commonly used option in a culture, it is a convention or habit or norm. If "it" is rejected by a majority in the culture, it is error. If "it" is rejected by many but still persists within the culture through an enclave of accepters, it is eccentricity. If "it" is something that already exists in the culture but is new for me, it is learning. If "it" is new to expert practitioners within its founding organization and stays within the organization, it is one of the terms used in Sternberg's (1999) propulsion model, such as redirection. If "it" is new to someone outside its founding domain but stays within the domain, it is innovation. If "it" is new to the culture and affects only the person who first considers it, it is insight, If "it" is new to the culture and it is shared and ripples to af- 
fect the whole culture, it is creativity.

In this thought exercise, then, the other terms are not dimensions, aspects, etc. or synonyms for creativity. They are precursors. Creativity is reserved for the "it" that shifts meaning for the whole culture. But by not calling all precursors also creativity, we can build clearer models regarding their relationships. This suggestion does not overcome the tendency for people to use whatever terms carry the most prestige and cache so that they might profit from the "boom time" for the "hot topic." But it does address some theoretical opportunities to define and fill in gaps among the wider array of terms, which using one term for all concepts obfuscates.

\section{Second, when is "it" creativity?}

As Glăveanu mentions in several locations in his critique, but never quite converges on, creativity - and many of its precursors - are time-dependent. However, this characteristic need not be framed as something to ignore, control for, or denigrate just because psychologists tend to use statistical models rather than dynamical models. Rather, it is something to embrace as one of the reasons we find creativity both so compelling and yet perplexing, and why our statistical findings often contradict. Understanding a particular creativity "it" depends not only on taking a perceiver perspective, but also a temporal perspective, as an anchor to interpret statistical findings.

Terms related to acceptance of a novelty - learning, innovation, insight, and creativity - usually apply to the first instance "it" is encountered. Furthermore, because we accept "it," we experience "it" as a beginning of a relationship with "it." Acceptance starts a clock, initiates a duration. However, terms related to rejection or containment of a novelty - error, eccentricity - are not often given duration because they are ignored, forgotten, so they do not "start the clock" for the person or group who encountered "it." There is no further processing, and if further processing is thrust upon the rejecters, they become irritated. The Laggards in product life-cycle or diffusion-of-innovation models (Rogers, 1962) who do not accept the innovation tend to be curmudgeons about "it" as long as it stays popular with other people (just ask the people without smartphones or Facebook pages!).

Acceptance of a novelty for further processing starts a dynamic system of sharing/ diffusing "it" with others as well as use/adaptation of "it." Acceptance is not a moment or a self-contained event, like a date; it's a relationship. If further processing is a requirement of acceptance - for example, sharing "it" creates ripples through a culture mind-bymind - then creativity can't be verified prospectively. It is like a cancer diagnosis: we have tests for various risk factors or markers of the disease, but it is not given the label 
"cancer" until there is a mass of mutant cells that is malignant and spreadable. Furthermore, unbridled creativity that has no time to settle into new norms or habits will exhaust the resources of individuals and cultures. So perpetual "disruptive innovation" (Christensen, 1997) can upset more than a market, it potentially exhausts a culture. All of us are "at risk" for causing creativity - a shift of meaning that affects the whole culture - but a culture, like the human body, has an "immune system" to evaluate and possibly destroy meanings that might be corrupting to the culture's institutions. Similarly, all of us are "at risk" for accepting and perpetuating a new meaning or for stopping its spread. We are a culture's immune system. All of us are contributors to both cultural stability and transformation. The aggregation of our decisions and actions, acceptances and rejections, perpetuating what is already accepted and promoting alternatives, creates creativity.

The final implication of when is "it" creativity is that the highest creativity is when "it" lasts - it stands the test of time, goes beyond its own zeitgeist. In the creativity seminar I teach, I start by defining creativity in terms of what we now consider the most ordinary - the ideas, products, processes that are so common we take them for granted and no longer consciously think about them. Forks, the game of baseball, chairs, the number zero - all were once new to a person, then a group, then a culture, but then were deemed so useful that they ended up losing the title of "creativity." Creativity is like breaking an Olympic record or winning a beauty pageant. The moniker of "creative" like "record-breaker" or "queen" - lasts for only a short period, but the distinction of having held the title lasts as long as memory or documentation maintains the record of its occurrence. Even though Picasso's paintings or Einstein's theories are no longer cuttingedge in art or physics, they retain the prestige of having caused a large-scale shift in meanings among not only their contemporaries, but also later generations. Counterintuitively, institutionalization of "it" within a culture is the pinnacle of creativity. If "it" lasts, it transcends its own temporal boundaries of being labeled creative, and it casts a long shadow on the future. Unfortunately, using current methods, that shadow only becomes visible and recognized by looking back on and illuminating that future's past.

\section{REFERENCES}

Barron, F., \& Harrington, D. (1981). Creativity, intelligence, and personality. Annual Review of Psychology, 32, 439-476.

Becker, M. (1995). Nineteenth-century foundations of creativity research. Creativity Research Journal, 8, 3, 219-229.

Christensen, C. M. (1997), The innovator's dilemma: when new technologies cause great firms to fail, Boston, MA: Harvard Business School Press. 
Csikszentmihalyi, M. (1996). Creativity. New York: Harper Collins.

Feldhusen, J. F., \& Goh, B. E., (1995). Assessing and accessing creativity: An integrative review of theory, research and development. Creativity Research Journal, 8, 231-247.

Glăveanu, V. P. (2014). The psychology of creativity: A critical reading. Creativity. Theories - Research - Applications, 1, 10-32; DOI: 10.15290/ctra.2014.01.01.02.

Gardner, H. (1988). Creativity: An interdisciplinary perspective. Creativity Research Journal, 1, 8-26.

Guilford, J. P. (1970). Creativity: Retrospect and prospect. Journal of Creative Behavior, 4, 3, 149-170.

Hennessey, B. A., \& Amabile, T. M. (2010). Creativity. Annual Review of Psychology, 61, 569-598.

Moran, S. (2009). What role does commitment play among writers with different levels of creativity? Creativity Research Journal,21, 2-3, 243-257.

Moran, S. (2010). Commitment and creativity: Transforming experience into art. In C. Connery, V. John-Steiner, \& A. Marjanovic-Shane (Eds.), Vygotsky and creativity: A cultural-historical approach to meaning-making, play, and the arts (pp. 141-160). New York: Peter Lang.

Moran, S., \& John-Steiner, V. (2003). Creativity in the making: Vygotsky's contribution to the dialectic of creativity and development. In K. Sawyer et al., Creativity and development (pp. 61-90). New York: Oxford University Press.

Mumford, M. D. (2003). Where have we been, where are we going? Taking stock in creativity research. Creativity Research Journal, 15, 107-120.

Plucker, J. A., \& Runco, M. A. (1998). The death of creativity measurement has been greatly exaggerated: Current issues, recent advances, and future direction in creativity assessment. Roeper Review, 21, 36-39.

Rogers, E. (1962). Diffusion of innovations. Glencoe, IL: Free Press.

Runco, M. A. (2004). Creativity. Annual Review of Psychology, 55, 657-687.

Simonton, D. K. (2000). Creativity: Cognitive, personal, developmental, and social aspects. American Psychologist, 55, 1, 151-158.

Sternberg, R. J. (1999). A propulsion model of creative contributions. Review of General Psychology, 3, 83-100.

Sternberg, R. J., \& Lubart, T. I. (1996). Investing in creativity. American Psychologist, 51, 7, 677-688.

Corresponding author at: Seana Moran, Department of Psychology Clark University, Worcester, MA 01610-1477, USA

E-mail: SMoran@clarku.edu 